\title{
Review Article \\ River Cetaceans and Habitat Change: Generalist Resilience or Specialist Vulnerability?
}

\author{
Brian D. Smith ${ }^{1}$ and Randall R. Reeves ${ }^{2}$ \\ ${ }^{1}$ Ocean Giants Program, Wildlife Conservation Society, 2300 Southern Boulevard, Bronx, NY 10460, USA \\ ${ }^{2}$ Okapi Wildlife Associates, 27 Chandler Lane, Hudson, QC, Canada JOP 1 HO \\ Correspondence should be addressed to Brian D. Smith, bsmith@wcs.org
}

Received 5 February 2012; Revised 13 March 2012; Accepted 14 March 2012

Academic Editor: E.C.M. (Chris) Parsons

Copyright (C) 2012 B. D. Smith and R. R. Reeves. This is an open access article distributed under the Creative Commons Attribution License, which permits unrestricted use, distribution, and reproduction in any medium, provided the original work is properly cited.

\begin{abstract}
River dolphins are among the world's most threatened mammals, and indeed the baiji (Lipotes vexillifer), a species endemic to China's Yangtze River, is likely extinct. Exploitation for products such as meat, oil, and skins has been a lesser feature in the population histories of river dolphins compared to most large mammals. Habitat factors are therefore of particular interest and concern. In this paper we attempt to describe the population-level responses of river dolphins to habitat transformation. We find circumstantial but compelling evidence supporting the view that, at a local scale, river dolphins are opportunists (generalists) capable of adapting to a wide range of habitat conditions while, at a river basin scale, they are more appropriately viewed as vulnerable specialists. The same evidence implies that the distributional responses of river dolphins to basinwide ecological change can be informative about their extinction risk, while their local behaviour patterns may provide important insights about critical ecological attributes. Empirical studies are needed on the ecology of river cetaceans, both to inform conservation efforts on behalf of these threatened animals and to help address broader concerns related to biodiversity conservation and the sustainability of human use in several of the world's largest river systems.
\end{abstract}

\section{Introduction}

In this paper, we attempt to evaluate the ability of river dolphins to adapt to environmental change. This evaluation is necessarily speculative and largely theoretical. Our goal is to develop ideas and terminology that will facilitate a rigorous debate and stimulate field researchers and resource managers to look at these animals with fresh eyes.

Our evaluation is far from academic because the fluvial systems occupied by dolphins have been and continue to be subjected to dramatic environmental changes associated with water development, a general decline in the availability and quality of fresh water, and global climate change. Regarding this last, although global warming will generally result in increased precipitation, the effects will be spatially and temporally uneven, and declines are expected in some areas [1]. Also, sea-level rise is expected to result in the loss of dolphin habitat in the lower reaches of rivers due to salinity encroachment and increased sedimentation [2].
The recent extinction of the Yangtze River dolphin or baiji Lipotes vexillifer [3] adds a sense of urgency for understanding the vulnerability and resilience of freshwater dolphins to environmental change. Although fishery interactions were probably the primary cause of the baiji's precipitous decline [4], the construction of extensive flood control, hydropower, and irrigation projects in the Yangtze River and its tributaries, resulting in extensive habitat loss [5], was almost certainly a contributing factor [6].

This paper consists of three main parts. First, we introduce the species, their taxonomic and ecological groupings, habitat selection, and social ecology. Next, we attempt to analyze the adaptability of these animals to variable environmental conditions, and, by inference, we consider whether they are better described as generalists or specialists according to particular criteria. Finally, we identify ways in which river dolphins might and might not be regarded as indicator species or, alternatively, as informative species. 


\section{The Species and Their Habitat}

2.1. Systematics and Taxonomy. Adaptation to fluvial habitat provides an organizing principle for our concept of river dolphins in this chapter. Cassens et al. [7] described the river dolphins as "a wastebasket nonmonophyletic ... taxon consisting of relict dolphin lineages from the Eocene, Oligocene, and early Miocene" that developed extreme ecological specialization. Those authors were referring to what are sometimes regarded as the "true" river dolphins belonging to four extant families: Platanistidae, Lipotidae (although this family is now likely extinct), Iniidae (Table 1), and Pontoporiidae. Although the systematics and taxonomy are still unsettled, for convenience, we accept Rice's [8] synthesis. He considered each of the four families to contain only a single living species, each endemic to a well-defined and restricted geographic setting. In two cases, he designated subspecies. Thus, Platanistidae consists of the "blind" dolphins of the South Asian subcontinent: species Platanista gangetica, subspecies P. g. gangetica (Ganges or gangetic dolphin), and P. g. minor (Indus dolphin); Iniidae consists of the species Inia geoffrensis of South America, with the subspecies I. g. geoffrensis (Amazon dolphin or boto), I. g. humboldtiana (Orinoco dolphin), and I. g. boliviensis (Bolivian dolphin of the Madeira River drainage). In both families, there is ongoing debate on whether multiple species should be recognized. No such debate surrounds the other two families - Lipotidae, consisting of Lipotes vexillifer, the baiji, and Pontoporiidae, consisting of Pontoporia blainvillei, the franciscana or La Plata dolphin. The latter is anomalous as it lives in estuarine and coastal marine, not fresh, waters along the eastern coast of South America and is not considered further here. Its inclusion among the "true" river dolphins is based on superficial similarities of skull features and body morphology, probably the result of convergent evolution from inhabiting a similarly turbid environment [7].

Although perhaps not as extreme, the adaptations to life in fresh water exhibited by several other primarily marine cetacean taxa are noteworthy. These, what we call facultative (as opposed to obligate) river cetaceans (Table 2), are dolphins of the genus Orcaella and genus Sotalia, and the narrow-ridged finless porpoises (Neophocaena asiaeorientalis). The systematics and taxonomy of these genera have been and remain in considerable flux. Orcaella was divided recently into two species, the Irrawaddy dolphin O. brevirostris and the snubfin dolphin O. heinsohni [9] but only the former has freshwater-living populations (in the Irrawaddy, Mekong, and Mahakam rivers of Southeast Asia). Sotalia, too, was divided recently into two species [10], with the tucuxi S. fluviatilis apparently confined to the Amazon system (which would make it an obligate freshwater species) and the Guiana dolphin S. guianensis occurring in coastal marine waters of northeastern South America and eastern Central America but also far up the Orinoco River of Venezuela (making it a facultative freshwater species). Due to the close taxonomic affinity of these two species and recent splitting of them (which means that most of the literature lumps them together) and their distinct evolutionary differences from the "true" river dolphins, which all have much longer species' histories and occupy their own families, we provisionally treat both the tucuxi and the Guiana dolphin as facultative freshwater species. We acknowledge, however, that this situation presents an exception to the concept of obligate (or "true") versus facultative freshwater cetaceans and may challenge our theory (explained below) about their respective differences as resilient generalists or adaptive specialists. A similar situation exists for the finless porpoises. One population of the narrow-ridged species (subspecies N. a. asiaeorientalis) occurs throughout the Yangtze River system in China. It was sympatric with the baiji and its historic range extended all the way from Three Gorges to the South China Sea, including large appended lakes (Poyang and Dongting).

\subsection{Anatomical and Behavioural Adaptations to a Running-} Water Environment (Including River-Appended Lakes and Flooded Forests). The three living forms of "true" river dolphins that inhabit rivers and lakes share superficial morphological traits, including reduced eyes, large paddle-like flippers, unfused cervical vertebrae (which allows considerable neck movement), and a long, narrow rostrum (beak) with numerous sharply pointed teeth. Considering the early divergence of the "true" river dolphins within the order Cetacea $[11,12]$, these shared features offer an excellent example of convergent evolution.

The loss of visual acuity is presumably related to its high metabolic cost and the limited usefulness of vision in the highly turbid waters that generally distinguish the habitat of these dolphins. As implied earlier, the Ganges and Indus dolphins are functionally blind: their eyes lack a crystalline lens. They are likely able to distinguish up from down during daylight but otherwise depend on a sophisticated auditory sense, including echolocation, to navigate, avoid obstacles, and capture prey.

A long, narrow beak, large flippers, and flexible neck provide obvious foraging advantages in freshwater environments, which are generally characterized by a greater degree of structural complexity, including local hydraulics, compared to coastal and pelagic marine waters. In the case of botos, these traits enable the animals to take advantage of foraging opportunities that arise as rivers spill over their banks and inundate the surrounding forest [13]. They enter the forest and chase and capture fish (and other organisms such as molluscs, crustaceans, and young turtles) among submerged roots, branches, and tree trunks. Botos are unique among toothed cetaceans in having differentiated teeth, with the posterior ones cusped and capable of crushing armoured catfish that are included in their catholic diet [13]. Whether the other river dolphins similarly foraged in the same kind of habitat before the surrounding land was deforested and the rivers were entrained by embankments and infested with other water regulation structures is unknown. In South Asian river dolphins, an extraordinarily long beak, sometimes curved to one side at the tip, is sexually dimorphic to females [14]. These dolphins have been observed rooting around with their beaks in the nooks and crannies of woody debris, attempting to catch fish associated with this type of microhabitat structure [15]. 


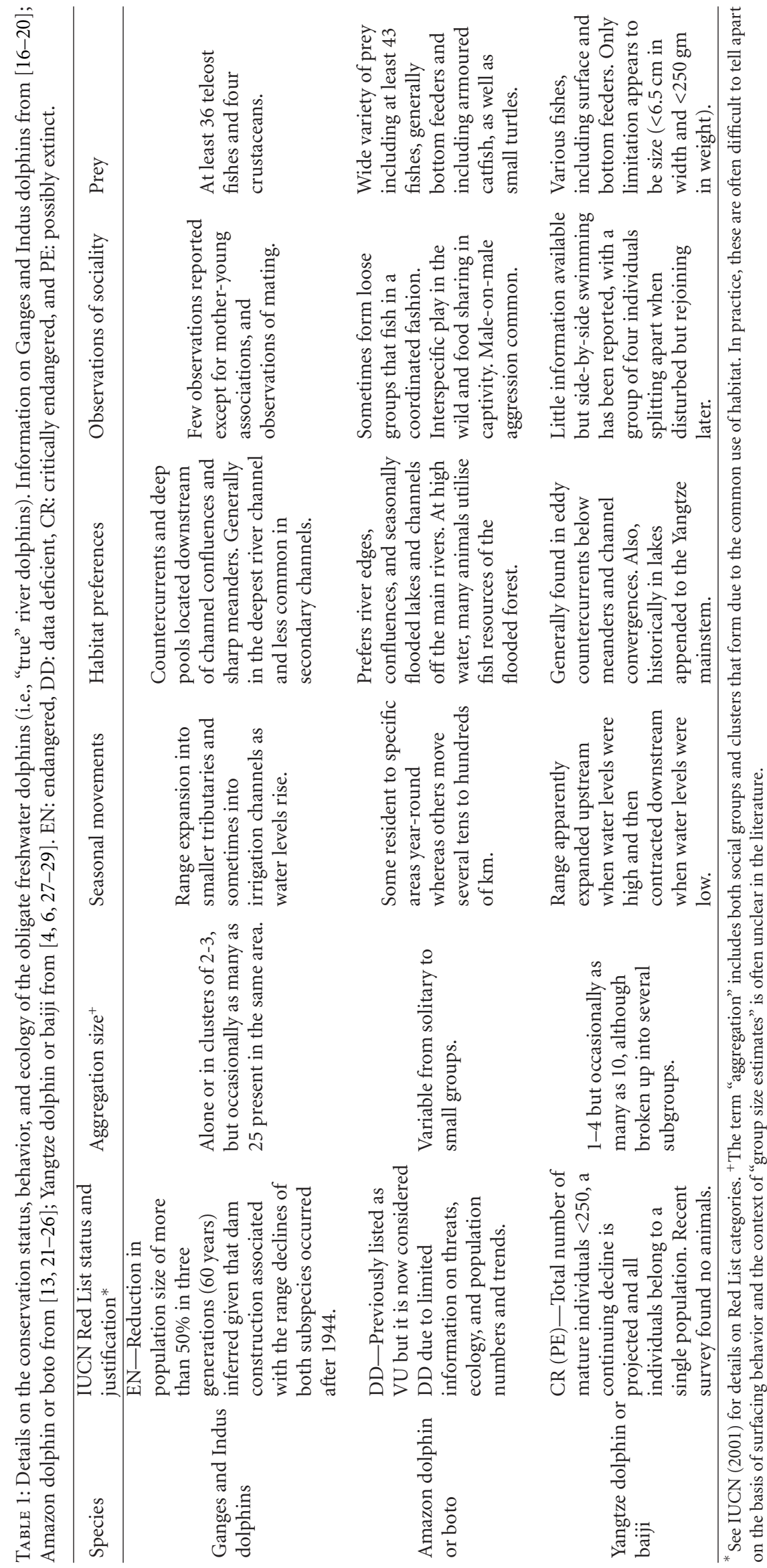




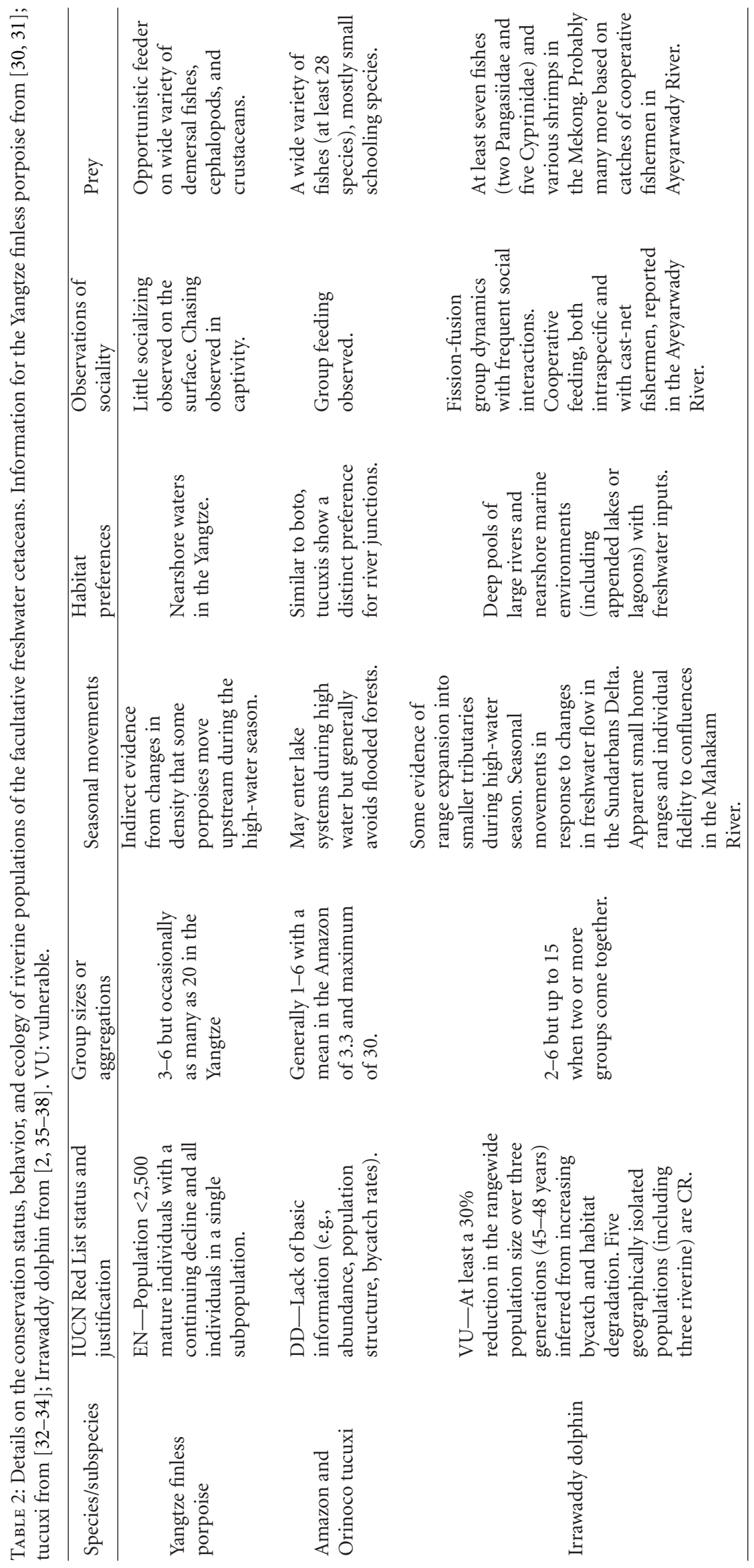


A striking feature of the boto's habitat is its dramatic seasonal variability. As summarized by Martin and da Silva [13] referring to the central Amazon, Brazil, "from low to high water the main rivers lose sandbanks and associated shallows, lowland forest is flooded to a depth of several metres, and floodplain depressions become lakes. All these changes are matched by large-scale movements of fish." In contrast to Amazonia (and Orinoquia, the other major aquatic system occupied by botos; cf. [39]), the fluvial systems currently inhabited by the South Asian river dolphins and (until recently) baijis have been transformed by centuries of human occupation and endeavour. Although considerable seasonal flux in water levels and riverbed morphology still occur in these latter systems, the scale, timing, and complexity of that flux have unquestionably changed as a result of deforestation, the construction of dams and embankments, and a declining water table. It is nevertheless reasonable to assume that selective forces broadly similar to those of the Amazon have helped shape the socioecology of Asian river dolphins on an evolutionary timescale.

Life for cetaceans in running-water environments is more energetically demanding than in oceanic environments because these animals must constantly swim upstream just to maintain their position along the river's axis. A behavioural response exhibited by river dolphins to this challenge is a distinct preference for occupying countercurrent pools where they find refuge from downstream currents and where much of the biological productivity is concentrated. Their affinity for countercurrents is probably most pronounced in the far upstream reaches of their range (i.e., in low-order tributaries) where the forces of downstream flow, due to a relatively steep geomorphic slope, are most intense (e.g., in the Karnali River, Nepal [15]), and least pronounced in the mainstem of large rivers where countercurrents are less circumscribed (e.g., in the Brahmaputra [40]). A strong affinity for countercurrents has also been noted for Ganges River and Irrawaddy dolphins at the ecotonal limit of the downstream range of the former species and the upstream range of the latter species in the Sundarbans mangrove forest, where tidal currents also contribute to the hydraulic structure of their running-water habitat $[2,41]$.

With regard to social ecology, is there anything in the social organisation or affiliative behaviour of river cetaceans that might be interpreted as an adaptation to living in a riverine, or indeed lacustrine, environment? Factors that could influence sociability are (a) defence against predation or bullying, (b) foraging efficiency (e.g., resource partitioning, cooperation in detection of food patches, cooperative capture of prey), (c) enhancement of reproductive success (e.g., communal care of young, territoriality), and (d) avoidance of inbreeding (i.e., enhancing genetic fitness).

Although the individual and group behaviour of the "true" river dolphins has been little studied, available information suggests they are generally less sociable than most marine cetaceans. Their group sizes are generally small (especially compared to most other toothed cetaceans); few interspecific interactions, with the exception of mating and in the case of botos male-on-male aggression, have been reported; the sole attractive force for animal clusters, with the exception of mother-young pairs, appears to be the concentrated nature of resources and hydraulic refuge in river systems, including appended water bodies.

Far from being maladaptive, the relatively low sociability of these species probably confers distinct advantages for a large, mobile predator living in riverine and backwater environments. With the exception of humans, river dolphins have no known predators, so the protective advantages of group living are largely irrelevant. Although temporally and spatially variable, the locations of their food are predictable at a river basin level according to hydrological cues from the seasonal flood pulse and at a local level according to geomorphic, hydraulic, and vegetative structure. This means that the detection of food patches is probably not an important factor selecting for sociability. The argument could be made that communal defence of food patches selects for group living. However, the temporal dynamism, three-dimensional character, and physical properties of lotic systems (which limit the potential range of sensory perception despite the fact that river dolphins are equipped with highly adaptive and effective echolocation abilities) imply that establishing and maintaining defensible territorial boundaries would be difficult at best, regardless of whether the animals occurred in groups or as individuals. In terms of reproductive success, including avoidance of inbreeding, the predictable but dynamic and difficult-to-defend patches of hydraulic refuge and food and the higher travel costs (see [42]) associated with running waters (which would particularly affect newborn animals) suggest that nongregariousness would be adaptive to the circumstances of life in a riverine environment.

A caveat is that the difference in sociability between the "true" river dolphins and the facultative freshwater species, which are more inclined towards group living, might imply that selective forces affecting river cetaceans can be attractive as well as repellent (even in the same rivers-e.g., the Orinoco and Yangtze where obligate and facultative freshwater species are, or once were, sympatric or partially so), depending on a species' evolutionary niche. Irrawaddy dolphins, tucuxis, and possibly finless porpoises are notably more social than the "true" river dolphins. For example, Irrawaddy dolphins exhibit cooperative feeding behaviour $[35,43]$, as well as fission-fusion activity, meaning that, during only a few surfacings, the animals split into multiple groups and then coalesce into a single group and then split apart again into some other configuration [44]. Tucuxis also forage in groups, converging simultaneously around a fish school, as well as alone [32].

In the case of the Sundarbans mangrove forest where the ranges of Ganges River and Irrawaddy dolphins meet, the former clearly dominate in freshwater areas and the latter are generally limited to areas with salinity levels greater than about $5 \mathrm{ppt}$, with distinct environmental partitioning between the two species, according to isohaline gradients. This might imply that the upstream range of Irrawaddy dolphins is more constrained by interspecific competition with Ganges river dolphins than by a dependence on a particular salinity threshold [2]. In fact, Irrawaddy dolphins occur far upstream in three other large Asian rivers (Ayeyarwady, 
Mekong and Mahakam; see [45]) that are not inhabited by Ganges or Indus river dolphins.

\section{Are River Dolphins Specialists or Generalists?}

In exploring the subject of specialist versus generalist tendencies, we are well aware of the difficulty of defining "river dolphin" and therefore of the risk of painting our story with too broad a brush. In other words, there is danger that generalist resilience ascribed to one species could be mistakenly extrapolated to another species simply because both are cetaceans living in freshwater systems. One might expect, a priori, that the boto, baiji, and South Asian river dolphins, found solely in freshwater habitat, would be more specialized than the Guiana and Irrawaddy dolphins and finless porpoises, all of which occur across the spectrum of habitats from marine to estuarine to fluvial.

Although the emphasis of this paper is on the obligate river dolphins, comparisons with the facultative freshwater species provide some of the most compelling evidence supporting the view that, at a local scale, the obligate species are opportunists (generalists) capable of adapting to a wide range of environmental conditions while, at a river basin scale, they may be pushing the limits of their ecological resilience, more closely resembling specialists.

Similar to the other "true" river dolphins, baijis had an awkward appearance and their swimming performance and respiration rates were described as relatively slow compared to those of the much more streamlined and active finless porpoises [27, 46]. The slower swimming speed and longer dive times of baijis were probably related to their strong affinity for deep pools located within the hydraulic refuge of countercurrents [28]. Less is known about the habitat selection of finless porpoises, but they appear to be far more flexible in terms of the riverine environments they occupy.

Numerous surveys in the Yangtze River have indicated a declining population of finless porpoises, especially in the upper reaches where baijis seem to have disappeared earlier than in the middle and lower reaches [47]. The immediate cause of the precipitous decline of baijis was probably direct mortality from entanglement in gillnets, snagging on longlines with multiple hooks, and electrocution from illegal fishing with electricity. However, the massive alteration of their riverine habitat caused by water engineering projects (see [5]) was almost certainly a contributing factor. One of the primary impacts of such projects was the simplification of river channels (i.e., countercurrents were reduced in size or eliminated as waterways became more canal-like in their geomorphic structure). It is possible that, at a local level, the affinity of baijis for countercurrents promoted generalist tendencies, allowing the animals to take advantage of the high diversity of prey supported by the abundant microhabitats occurring within these hydraulically complex nodes. However, at a river-basin level, their dependence on these fluvial features probably put them at increased risk as humans transformed the river and its appended lake systems. In contrast, finless porpoises may be somewhat better adapted (due in part to their more streamlined body shape) to survive in running waters with reduced hydraulic refuge. Admittedly, this supposed difference is based solely on circumstantial evidence. If true, however, it would mean that baijis could be considered generalists at a local scale, which might help explain why they managed to survive in much of the Yangtze River system from the middle Miocene (see [11]) to the present day (almost), despite centuries of relatively intense and prolonged human activity on and along the river. In contrast, they would have to be considered specialists at the basin scale, having finally proven unable to adapt to the wholesale transformation of the Yangtze system achieved by human activity in the 20th century. Finless porpoises, on the other hand, appear to exhibit generalist tendencies at both local and river basin scales. This would imply that their conservation prospects in the Yangtze are at least somewhat more favorable than those of the baiji, although even the most resilient generalists have their ecological limits, as humans in some areas are beginning to find (e.g., with famines in much of sub-Saharan Africa transforming previously productive lands into barren deserts). Also, as Zhao et al. [47] emphasized, the continuing threat of incidental mortality in fisheries may yet prove sufficiently potent to nullify any resilience the porpoises may have in terms of adapting to environmental change.

No facultative freshwater cetaceans occur within the range of Ganges and Indus dolphins, except as mentioned above in a very narrow, seasonally mobile band of distributional overlap between Irrawaddy and Ganges dolphins in the Sundarbans mangrove forest. This situation might be expected, given that Platanista (a sister taxon to all other members of the Odontoceti suborder [11]) has had since the late Neogene, when it remained in shrinking epicontinental seas as sea levels receded, to finely tune its adaptations to a running-water environment. This long evolutionary history probably allowed Platanista to become an unrivalled freshwater specialist, occupying a wide range of ecological niches that might otherwise be available for potential range extensions of facultative freshwater cetaceans (e.g., Irrawaddy dolphins or finless porpoises that inhabit adjacent coastal waters). Indeed, Miller [48] distinguished Platanista as the most highly modified species within the order Cetacea. It follows that the other obligate river dolphins appeared much later in the middle Miocene and share their habitat today with facultative freshwater cetaceans. Interestingly, the only large, mobile predator that may have rivalled the dominance of Platanista in the Ganges and Indus rivers is the gharial Gavialis gangeticus, a critically endangered [49], exclusively riverine, and piscivorous crocodilian that, similar to Ganges and Indus river dolphins, is a monotypic, relict species with a highly modified long snout-another striking example of convergent evolution.

The apparent contradiction between Platanista's identification as a running-water specialist, and at the same time as a species with generalist tendencies allowing it (both subspecies) to essentially monopolize the ecological niches available for secondary occupancy by other cetaceans, may be resolved by considerations of scale (river-basin versus habitat). Support for considering Ganges and Indus dolphins to be resilient generalists at the habitat scale but vulnerable 
specialists at the river-basin scale can be inferred from their population-level responses to habitat modification. Extensive flow regulation structures were built, mostly in the 1950s through 1980s, in both the Ganges (at least 19 high dams (defined as an artificial barriers with a height of $15 \mathrm{~m}$ or more that are constructed across a watercourse to impound water and regulate flow for generating hydroelectricity and flood prevention) and 23 barrages (defined as low-gated dams used to divert water for irrigation, flood control, and/or navigation purposes; normally the gates remain closed during the low-water season and are opened during the high-water season with differing levels of regulation in between)) and Indus (at least 8 high dams and 17 barrages) systems [5]. Prior to that construction binge, the distribution of both subspecies reportedly extended to the Himalayan foothills where rocky barriers, high water velocity, or shallow water blocked farther upstream movement by dolphins [50]. Not surprisingly, marked declines have occurred in the ranges of both subspecies since the 19th century.

In the Indus, dolphins historically occurred in approximately $3,400 \mathrm{~km}$ of the main channel and its tributaries, but they are now found in only about 1,000 linear km of downstream reaches in the main channel, with $99 \%$ confined to a 690 linear $\mathrm{km}$ segment [16]. In the Ganges system, the situation is less clear, but substantial portions of the dolphins' range, particularly in upstream areas, have been lost. For example, no dolphins have been reported in recent years in a river segment approximately $100 \mathrm{~km}$ long between the Madhya Ganga Barrage and the Bhimgoda Barrage, at the upstream limit of their historical range in the Ganges [51]. In recent years, dolphins have not been reported in the Yamuna River above the Chambal River confluence during the dry season but that segment might still be occupied during the high-water season [51]. Historically, dolphins were found year-round in the Yamuna River about $400 \mathrm{~km}$ upstream to Delhi [50]. Finally, Ganges dolphins apparently have also been extirpated from a 300 linear $\mathrm{km}$ segment of the Son River, above and below the Indrapuri Barrage (at least during the dry season) and upstream of the Ganges confluence [52].

It is difficult to differentiate between the impacts of population fragmentation [53] and habitat degradation [54] caused by dam construction, but a clear pattern of extirpation from upstream segments, where the animals are probably more dependent on hydraulic complexity, is evident from the reported range declines summarized above. In the middle and lower reaches of the main channel, where the animals may have more flexibility in how they use habitat due to the less circumscribed nature of countercurrents and the greater availability of hydraulic refuge induced by minor geomorphic features (e.g., slight sinuosity) and where greater productivity is generally realized from the seasonal flood pulse, "densities" of both species remain quite high. For instance, a mean encounter rate of 1.8 dolphins/linear $\mathrm{km}$ was reported for the Vikramshila Gangetic Dolphin Sanctuary [17] in approximately the middle of the Ganges River, and 3.6 dolphins $/ \mathrm{km}$ in the Sindh Dolphin Reserve between the Guddu and Sukkur barrages slightly downstream of approximately the middle of the Indus River [16]. In the latter, the dolphin population is believed to be increasing, due to either unidirectional immigration from upstream segments of the river (as dolphins move downstream through barrage gates but presumably have difficulty returning due to high-velocity, turbulent flows), increased recruitment within the Guddu-Sukkur segment following implementation of a ban on hunting in 1972, or some combination of both [16].

The dramatic range declines of both Ganges and Indus dolphins constitute a significant threat to the survival of Platanista (which, as was the case with the baiji, means the survival of an entire mammalian family). Nonetheless, their apparently high population densities where suitable habitat remains, in many cases despite local factors threatening both subspecies (e.g., incidental catches, illegal hunting, pollution), suggest that these dolphins are fairly resilient (albeit within limits) as generalists at a habitat scale but exceedingly vulnerable as specialists at a river basin scale. Also, it again implies that the distributional responses of Platanista populations to basin-wide ecological impacts (whether humaninduced or natural) are informative about their extinction risk, as well as about declines in associated biotic diversity, while their local behaviour patterns may provide important insights about the ecological characteristics of their habitat.

\section{River Dolphins as Indicator or Informative Species}

Zacharias and Roff [55] differentiate between "compositional indicators," which signify a particular habitat, community, or ecosystem, and "condition indicators," which are used for biological monitoring of environmental changes resulting from anthropogenic and natural disturbances. At face value, river dolphins make poor compositional or condition indicators. Indeed, the species often appear to satisfy their life history needs in environmental conditions that are "in every sense marginal" [56], and their life history characteristics are opposite of what are generally considered necessary for scientifically defensible indicators, including occupation of a highly specific ecological niche (see [57]). However, as large, mobile predators, the manner by which river dolphins satisfy their life history needs (e.g., movement patterns, habitat use, foraging behaviour, etc.), may give them particular value for identifying ecologically significant attributes, including local aggregations of biological productivity for site-based protection, and for monitoring changes in these parameters. We suggest that using the indicator properties of cetaceans (i.e., observable adaptive responses), rather than simple measures of animal presence-absence or relative abundance, makes it possible to turn the concept of indicator species on its head. In other words, the very plasticity of cetaceans, which is a feature that in some ways undermines their utility as conventional compositional or condition indicators, can be used for making certain ecological inferences.

The term generalist carries the unfortunate connotation of haphazard indifference to habitat, whereas the concept of adaptive resilience implies an ability to exquisitely apply an array of specific survival and reproductive strategies under a range of environmental conditions. Thus, even though the basic resources needed by a generalist for survival may 
be generic-food, refuge from energy-draining, and injurious environmental forces, reproductive opportunities the strategies river dolphins use to gain access to such resources and their adaptive responses to changing conditions can be informative about critical habitat features. One advantage of cetaceans (versus most other aquatic species) as informative species is that they can be observed, counted, and tracked. One can tell where they are located and to a certain degree what they are doing simply by surface observations and also by listening (both above the water surface, where their respiration sounds are often heard, and underwater, where their vocalizations are virtually constant).

Homo sapiens, a quintessential generalist, can hardly be considered an indicator or informative species nowadays. We sequester and consume vastly more resources than are needed to sustain and perpetuate our own species, and we have suppressed or obliterated many of the ecological feedback processes that might be informative, if not also indicative. However, in looking back on our days as huntergatherers, it could be argued that ours was, at that time, an informative species. As just one example, the controlled burning of grasslands by nomadic or seminomadic hunters would have demonstrated the importance of open forests and meadows to large herbivorous wildlife.

Understanding the habitat preferences of freshwater cetaceans and tracking changes in their fine-scale distribution has strong potential for informing us about habitat quality and perhaps, at least indirectly, the population status of other biota. By investigating and monitoring the physical and biological dependencies of river cetaceans and how these change in the context of altered environmental conditions, much can be learned about the conditions needed to conserve and maintain high levels of biological diversity and productivity in the river systems where these animals occur.

In assessing a species' value as an ecological indicator, it is necessary to differentiate between or among geographic scales. As generalists, freshwater cetaceans make poor indicator species, per se, but, at a local level, their adaptive resilience makes them particularly informative for understanding critical habitat features. For instance, at the far upstream range of their distribution, the wide variety of foraging strategies exhibited by Ganges River dolphins in the Karnali River provides information on the role of hydraulic complexity in structuring habitat and demonstrates the importance of woody debris for maintaining biological productivity in loworder tributaries that do not enjoy the same magnitude of nutrient influx from flood recession as downstream river segments. Similarly, information on the catholic diet of botos and their sexually dimorphic patterns of habitat use (see [21]) provide valuable clues about the local movements and environmental requirements of their diverse prey.

Meanwhile, at a river-basin level, the specialist tendencies of "true" river dolphins can be informative about critical ecological processes. These species are profoundly tied to the physical characteristics of their environment. Besides their need for osmotic regulation, they require sufficient freshwater flow to allow movement between deep pools and they need access to hydraulic refuge from high-velocity currents [54]. Their movement patterns and fine-scale distribution may therefore be informative about the hydrologic regimes (e.g., timing and magnitude of the seasonal flood pulse) and sediment dynamics (e.g., erosion and deposition patterns) needed for maintaining native species diversity and abundance in large floodplain rivers, which are coming under increasing stress from human use and abuse. For instance, understanding and monitoring the ecology of Ganges River and Irrawaddy dolphins in the Sundarbans mangrove forest may provide useful insights on the impacts of declining freshwater supplies and sea-level rise [2]. Such insights may, in turn, contribute to the development of adaptive management strategies that allow biodiversity to be conserved even as human communities themselves struggle to adapt and survive in a rapidly changing environment.

\section{Conclusion}

As mentioned at the beginning, the aim of this paper was to develop ideas and stimulate debate concerning the generalist and specialist characteristics of river cetaceans and to point out ways that observations of these animals might be informative concerning the environments where they live. Among the topics discussed were the importance of considering geographic scale, probable differences in the resilience to environmental change between the obligate and facultative freshwater cetaceans, and the relative value of both species groups for identifying and monitoring habitat attributes and ecosystem processes.

Each of the obligate freshwater dolphin species is uniquely situated along a spectrum of human-induced disturbance and species endangerment, with the position (or status) of the boto being the most favourable, albeit still vulnerable, within the comparatively undisturbed Amazon, Madeira and Orinoco basins. The Ganges and Indus dolphins are endangered within the highly modified Indus and Ganges river basins, and the baiji is functionally if not entirely extinct, having been drawn into what might be described as a classic extinction vortex in the extremely modified and degraded Yangtze Basin. Regardless of how discouraging this interpretation of the situation may be, it allows one to see how the various species might be used to inform freshwater conservation and management. Thus, the boto might be regarded as a "control" of sorts, the Ganges and Indus dolphins as subjects of experimental manipulation (living as they do in highly modified systems but with remaining patches of relatively high-quality habitat), and the baiji as an extreme demonstration of the limits of resilience or, put another way, an example of the inevitable consequences of complacency and inaction.

Perhaps the most definitive conclusion that can be drawn from this paper is that more empirical studies are needed on the habitat preferences and ecology of freshwater cetaceans (although for the baiji, this would have to be a retrospective analysis), both to inform conservation efforts on behalf of these endangered animals (whether as generalists, specialists or, depending on geographical scale, both) and to help address broader concerns related to biodiversity conservation and the sustainability of human use in several of the world's largest rivers systems. 
Two promising initiatives exemplify how these types of studies have already been used for conservation planning: the South American River Dolphin Protected Area Network and the Bangladesh Cetacean Diversity Protected Area Network, the latter also including marine species [58]. Both initiatives seek to conserve freshwater cetacean diversity (Amazon, Bolivian, Orinoco, Guiana, and tucuxi dolphins in the former; Ganges and Irrawaddy dolphins in the latter) at a variety of spatial scales and to use ecological information from priority habitat to better understand alterations in river-basin processes, due to water development and climate change, and inform adaptive conservation management.

\section{Acknowledgments}

This paper was improved by constructive comments from Tony Martin, Gill Braulik, and two anonymous reviewers. Support for Brian Smith's time while working on this paper was provided by the Wildlife Conservation Society.

\section{References}

[1] Intergovernmental Panel on Climate Change (IPCC), "Climate change 2007: the physical basis, summary for policy makers," World Meteorological Organization and United Nations Environmental Program, 2007, http://www.ipcc.ch/ publications_and_data/ar4/wg1/en/contents.html.

[2] B. D. Smith, G. Braulik, S. Strindberg, R. Mansur, M. A. A. Diyan, and B. Ahmed, "Habitat selection of freshwaterdependent cetaceans and the potential effects of declining freshwater flows and sea-level rise in waterways of the Sundarbans mangrove forest, Bangladesh," Aquatic Conservation, vol. 19, no. 2, pp. 209-225, 2009.

[3] S. T. Turvey, R. L. Pitman, B. L. Taylor et al., "First humancaused extinction of a cetacean species?" Biology letters, vol. 3, no. 5, pp. 537-540, 2007.

[4] X. Zhang, D. Wang, R. Liu et al., "The Yangtze River dolphin or baiji (Lipotes vexillifer): population status and conservation issues in the Yangtze River, China," Aquatic Conservation, vol. 13, no. 1, pp. 51-64, 2003.

[5] B. D. Smith, R. K. Sinha, K. Zhou et al., "Register of water development projects affecting Asian river cetaceans," in Biology and Conservation of Freshwater Cetaceans in Asia, R. R. Reeves, B. D. Smith, and T. Kasuya, Eds., Occasional papers of the IUCN Species Survival Commission, no. 23, IUCN, Gland, Switzerland, 2000.

[6] B. D. Smith, K. Zhou, D. Wang et al., "Lipotes vexillifer," in: 2008 IUCN Red List of Threatened Species, 2008, http://www http://www.iucnredlist.org/.

[7] I. Cassens, S. Vicario, V. G. Waddell et al., "Independent adaptation to riverine habitats allowed survival of ancient cetacean lineages," Proceedings of the National Academy of Sciences of the United States of America, vol. 97, no. 21, pp. 11343-11347, 2000.

[8] D. W. Rice, Marine Mammals of the World, Systematics and Distribution, Society of Marine Mammalology, Lawrence, Kan, USA, 1998.

[9] I. Beasley, K. M. Robertson, and P. Arnold, "Description of a new dolphin, the Australian snubfin dolphin Orcaella heinsohni sp. N. (Cetacea, Delphinidae)," Marine Mammal Science, vol. 21, no. 3, pp. 365-400, 2005.
[10] S. Caballero, F. Trujillo, J. A. Vianna et al., "Taxonomic status of the genus Sotalia: species level ranking for "tucuxi" (Sotalia fluviatilis) and "costero" (Sotalia guianensis) dolphins," Marine Mammal Science, vol. 23, no. 2, pp. 358-386, 2007.

[11] H. Hamilton, S. Caballero, A. G. Collins, and R. L. Brownell Jr., "Evolution of river dolphins," Proceedings of the Royal Society $B$, vol. 268, no. 1466, pp. 549-556, 2001.

[12] M. Nikaido, F. Matsuno, H. Hamilton et al., "Retroposon analysis of major cetacean lineages: the monophyly of toothed whales and the paraphyly of river dolphins," Proceedings of the National Academy of Sciences of the United States of America, vol. 98, no. 13, pp. 7384-7389, 2001.

[13] A. R. Martin and V. M. F. da Silva, "River dolphins and flooded forest: seasonal habitat use and sexual segregation of botos (Inia geoffrensis) in an extreme cetacean environment," Journal of Zoology, vol. 263, no. 3, pp. 295-305, 2004.

[14] G. Pilleri and M. Gihr, "Differences observed on the skull of Platanista indi and gangetica," Investigations on Cetacea, vol. 4, pp. 44-70, 1971.

[15] B. D. Smith, "1990 Status and conservation of the Ganges River dolphin Platanista gangetica in the Karnali River, Nepal," Biological Conservation, vol. 66, no. 3, pp. 159-169, 1993.

[16] G. T. Braulik, "Status assessment of the Indus River dolphin, Platanista gangetica minor, March-April 2001," Biological Conservation, vol. 129, no. 4, pp. 579-590, 2006.

[17] S. K. Choudhary, B. D. Smith, S. Dey, S. Dey, and S. Prakash, "Conservation and biomonitoring in the Vikramshila Gangetic Dolphin Sanctuary, Bihar, India," Oryx, vol. 40, no. 2, pp. 189-197, 2006.

[18] R. R. Reeves, S. Leatherwood, and R. S. L. Mohan, A Future for Asian River Dolphins: Report from a Seminar on the Conservation of River Dolphins of the Indian Subcontinent, Whale and Dolphin Conservation Society, London, UK, 1993.

[19] B. D. Smith and G. T. Braulik, "Platanista gangetica" in: 2008 IUCN Red List of Threatened Species, 2008, http://www .iucnredlist.org/.

[20] B. D. Smith and G. T. Braulik, Susu and Bhulan. Encyclopedia of Marine Mammals, Academic Press, San Diego, Calif, USA, 2nd edition, 2009.

[21] A. R. Martin, V. M. F. da Silva, and D. L. Salmon, "Riverine habitat preferences of botos (Inia geoffrensis) and tucuxis (Sotalia fluviatilis) in the central amazon," Marine Mammal Science, vol. 20, no. 2, pp. 189-200, 2004.

[22] R. C. Best and V. M. F. da Silva, "Amazon river dolphin, boto Inia geoffrensis (de Blainville, 1817)," in Handbook of Marine Mammals: River Dolphins and the Larger Toothed Whales, S. H. Ridgeway and R. J. Harrison, Eds., vol. 4, Academic Press, London, UK, 1989.

[23] R. C. Best and V. M. F. da Silva, "Inia geoffrensis," Mammalian Species, vol. 426, pp. 1-8, 1993.

[24] S. Leatherwood, R. R. Reeves, B. Würsig et al., "Habitat preferences of river dolphins in the Peruvian Amazon," in Biology and Conservation of Freshwater Cetaceans in Asia, R. R. Reeves, B. D. Smith, and T. Kasuya, Eds., Occasional papers of the IUCN Species Survival Commission, no. 23, IUCN, Gland, Switzerland, 2000.

[25] A. R. Martin and V. M. F. da Silva, "Number, seasonal movements, and residency characteristics of river dolphins in an Amazonian floodplain lake system," Canadian Journal of Zoology, vol. 82, no. 8, pp. 1307-1315, 2004.

[26] R. R. Reeves, T. A. Jefferson, L. Karczmarski et al., "Inia geoffrensis," in: 2008 IUCN Red List of Threatened Species, 2008, http://www.iucnredlist.org/. 
[27] P. Chen, P. Liu, R. Liu et al., "The distribution, ecology, behaviour and protection of dolphins in the middle reach of Changjiang River (Wuhan-Yuayang)," Investigations on Cetacea, vol. 10, pp. 87-103, 1980.

[28] Y. Hua, Q. Zhao, and G. Zhang, "The habitat and behavior of Lipotes vexillifer," in Biology and Conservation of the River Dolphins, W. F. Perrin, R. L. Brownell Jr., K. Zhou et al., Eds., Occasional papers of the IUCN Species Survival Commission, no. 3, IUCN, Gland, Switzerland, 1989.

[29] K. Zhou and Y. Li, "Status and aspects of the ecology and behaviour of the baiji, Lipotes vexillifer in the lower Yangtze River," in Biology and Conservation of the River Dolphins, W. F. Perrin, R. L. Brownell Jr., K. Zhou et al., Eds., Occasional papers of the IUCN Species Survival Commission, no. 3, IUCN, Gland, Switzerland, 1989.

[30] Cetacean Specialist Group, "Neophocaena phocaenoides ssp. asiaeorientalis," 2008 IUCN Red List of Threatened Species. 2008 IUCN Red List of Threatened Species, 1996, http://www .iucnredlist.org/.

[31] T. A. Jefferson and S. K. Hung, "Neophocaena phocaenoides," Mammalian Species, vol. 746, pp. 1-12, 2004.

[32] V. M. F. da Silva and R. C. Best, "Tucuxi Sotalia fluviatilis (Gervais, 1853)," in Handbook of Marine Mammals, S. H. Ridgway and R. Harrison, Eds., vol. 5 of The first book of dolphins, Academic Press, London, UK, 1994.

[33] C. Faustino and V. M. F. da Silva, "Seasonal use of Amazon floodplains by the tucuxi Sotalia fluviatilis (Gervais 1853) in the central Amazon, Brazil," Latin American Journal of Aquatic Mammals, vol. 2, pp. 95-104, 2006.

[34] R. R. Reeves, E. A. Crespo, Dans et al., "Sotalia fluviatilis," in: 2008 IUCN Red List of Threatened Species, 2008, http:// www.iucnredlist.org/.

[35] B. D. Smith, H. Thant, J. M. Lwin et al., "Preliminary investigation of cetaceans in the Ayeyarwady River and northern coastal waters of Myanmar," Asian Marine Biology, vol. 14, pp. 173-184, 1997.

[36] D. Kreb, X. Budiono, and X. Syachraini, "Status and conservation of Irrawaddy dolphins Orcaella brevirostris in the Mahakam River of Indonesia," in Status and Conservation of Freshwater Populations of Irrawaddy Dolphins, B. D. Smith, R. G. Shore, and A. Lopez, Eds., WCS working paper, no. 31, Wildlife Conservation Society, Bronx, NY, USA, 2007.

[37] R. R. Reeves, T. A. Jefferson, L. Karczmarski et al., "Orcaella brevirostris," in: 2008 IUCN Red List of Threatened Species, 2008, http://www.iucnredlist.org/.

[38] B. D. Smith, Irrawaddy Dolphin. Encyclopedia of Marine Mammals, Academic Press, San Diego, Calif, USA, 2nd edition, 2009.

[39] T. L. McGuire and K. O. Winemiller, "Occurrence patterns, habitat associations, and potential prey of the river dolphin, Inia geoffrensis, in the Cinaruco River, Venezuela," Biotropica, vol. 30, no. 4, pp. 625-638, 1998.

[40] B. D. Smith, A. K. M. A. Haque, M. S. Hossain, and A. Khan, "River dolphins in Bangladesh: conservation and the effects of water development," Environmental Management, vol. 22, no. 3, pp. 323-335, 1998.

[41] B. D. Smith, M. A. A. Diyan, R. M. Mansur, E. F. Mansur, and B. Ahmed, "Identification and channel characteristics of cetacean "hotspots" in waterways of the Eastern Sundarbans mangrove forest, Bangladesh," Oryx, vol. 44, no. 2, pp. 241247, 2010.

[42] R. C. Connor, "Group living in whales and dolphins," in Cetacean Societies, Field Studies of Dolphins and Whales,
J. Mann, R. C. Connor, P. L. Tyack et al., Eds., University of Chicago Press, Chicago, Ill, USA, 2000.

[43] B. D. Smith, M. T. Tun, A. M. Chit, H. Win, and T. Moe, "Catch composition and conservation management of a humandolphin cooperative cast-net fishery in the Ayeyarwady River, Myanmar," Biological Conservation, vol. 142, no. 5, pp. 10421049, 2009.

[44] B. D. Smith, G. Braulik, S. Strindberg, B. Ahmed, and R. Mansur, "Abundance of irrawaddy dolphins (Orcaella brevirostris) and Ganges River dolphins (Platanista gangetica gangetica) estimated using concurrent counts made by independent teams in waterways of the sundarbans mangrove forest in Bangladesh," Marine Mammal Science, vol. 22, no. 3, pp. 527547, 2006.

[45] B. D. Smith, R. G. Shore, and A. Lopez, Eds., Status and Conservation of Freshwater Populations of Irrawaddy Dolphins, WCS working paper, no. 31, Wildlife Conservation Society, Bronx, NY, USA, 2007.

[46] K. Zhou, G. Pilleri, and Y. Li, "Observation on the Baiji (Lipotes vexillifer) and the finless porpoise (Neophocaena asiaeorientalis) in the Changjiang (Yangtze) River between Nanjing and Taiyangzhou, with remarks on some physiological adaptations of the Baiji to its environment," Investigations on Cetacea, vol. 10, pp. 109-119, 1980.

[47] X. Zhao, J. Barlow, B. L. Taylor et al., "Abundance and conservation status of the Yangtze finless porpoise in the Yangtze River, China," Biological Conservation, vol. 141, no. 12, pp. 3006-3018, 2008.

[48] G. S. Miller, "The telescoping of the cetacean skull," Smithsonian Miscellaneous Collections, vol. 76, pp. 1-70, 1923.

[49] B. C. Choudhury, L. A. K. Singh, R. J. Rao et al., "Gavialis gangeticus," 2008 IUCN Red List of Threatened Species, 2007, http://www.iucnredlist.org/.

[50] J. Anderson, Anatomical and Zoological Researches: Comprising an Account of Zoological Results of the Two Expeditions to Western Yunnan in 1868 and 1875; and a Monograph of the Two Cetacean Genera, Platanista and Orcella, Bernard Quaritch, London, UK, 1879.

[51] R. K. Sinha, B. D. Smith, G. Sharma et al., "Status and distribution of the Ganges susu, Platanista gangetica, in the Ganges river system of India and Nepal," in Biology and Conservation of Freshwater Cetaceans in Asia, R. R. Reeves, B. D. Smith, and T. Kasuya, Eds., Occasional papers of the IUCN Species Survival Commission, no. 23, IUCN, Gland, Switzerland, 2000.

[52] R. K. Sinha and G. Sharma, "Current status of the Ganges river dolphin in the rivers Kosi and Son," Journal of the Bombay Natural History Society, vol. 100, no. 1, pp. 27-37, 2003.

[53] R. R. Reeves and B. D. Smith, "Interrupted migrations and dispersal of river dolphins: some ecological effects of riverine development," in Proceedings of the Symposium on Animal Migration, Geneva, Switzerland, Bonn, Germany, 1999, CMS technical series publication no. 2 .

[54] B. D. Smith and R. R. Reeves, "Report of the workshop on the effects of water development on river cetaceans in Asia, Rajendrapur, Bangladesh, 26-28 February 1997," in Biology and Conservation of Freshwater Cetaceans in Asia, R. R. Reeves, B. D. Smith, and T. Kasuya, Eds., Occasional papers of the IUCN Species Survival Commission, no. 23, IUCN, Gland, Switzerland, 2000.

[55] M. A. Zacharias and J. C. Roff, "Use of focal species in marine conservation and management: a review and critique," Aquatic 
Conservation: Marine and Freshwater Ecosystems, vol. 11, no. 1, pp. 59-76, 2001.

[56] R. R. Reeves and P. J. H. Reijnders, "Conservation and management," in Marine Mammal Biology, an Evolutionary Approach, R. A. Hoelzel, Ed., Blackwell Science, Oxford, UK, 2002.

[57] G. K. Meffe and C. R. Carroll, "The species in conservation,” in Principles of Conservation Biology, G. K. Meffe, Ed., Sinauer Associates, Sunderland, Mass, USA, 2nd edition, 1997.

[58] E. Hoyt, Marine Protected Areas for Whales, Dolphins and Porpoise, a World Handbook for Cetacean Habitat Conservation and Planning, Earthscan, London, UK, 2nd edition, 2011. 

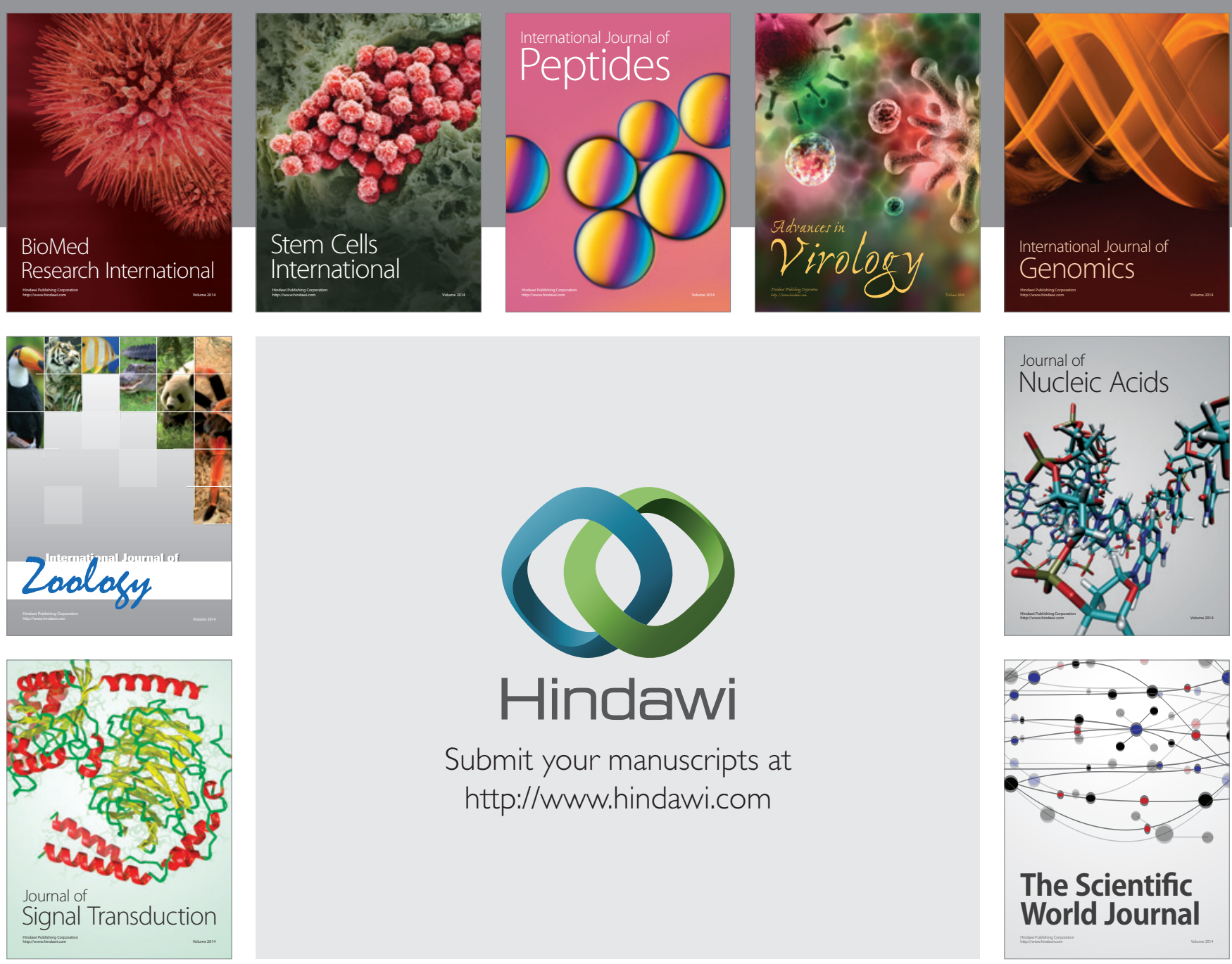

Submit your manuscripts at

http://www.hindawi.com


The Scientific World Journal
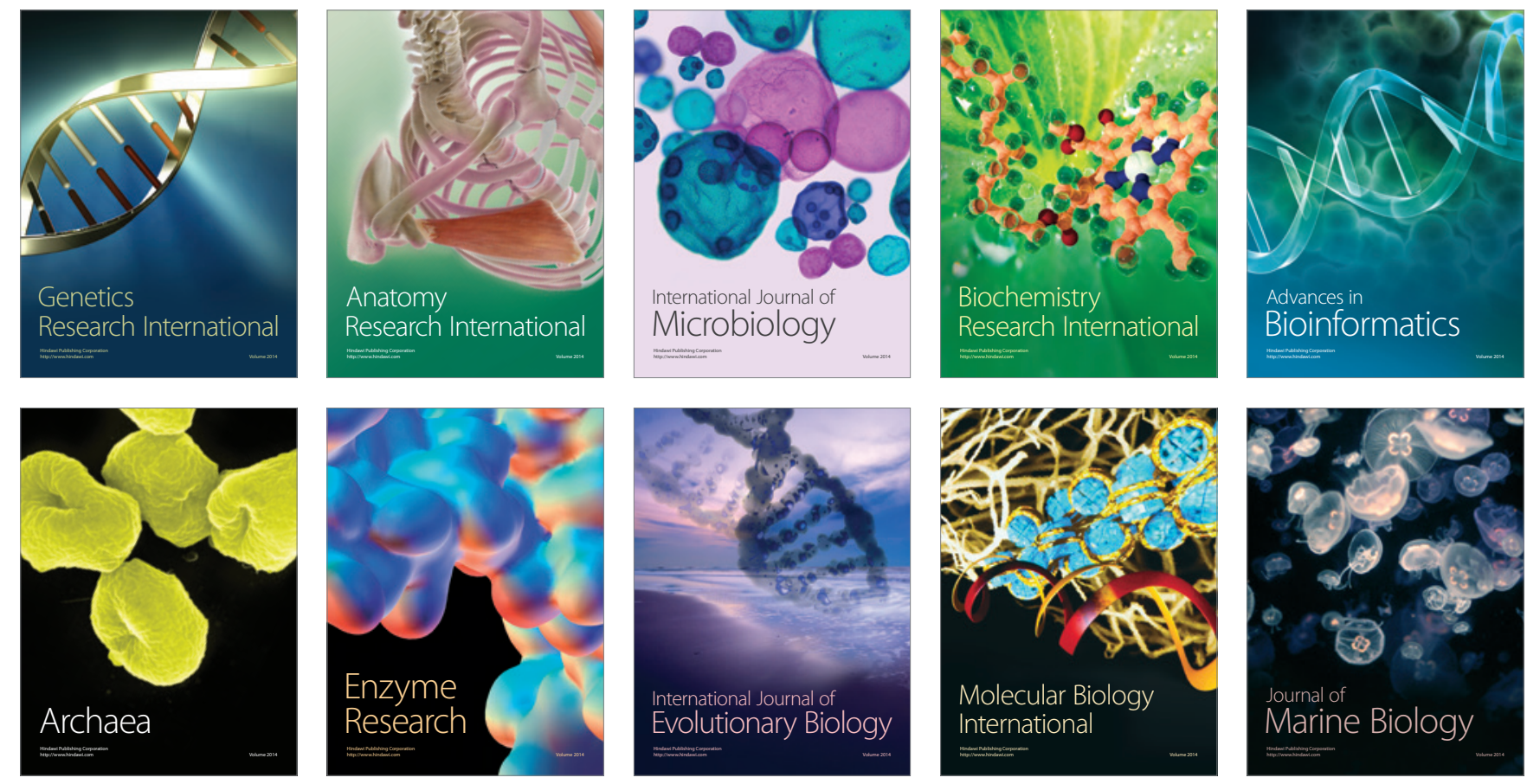